\title{
THE EPIDEMICAL PROFILE OF PATIENTS WITH \\ UTERINE SARCOMA TREATED AT INSTITUTO \\ BRASILEIRO DE CONTROLE DO CÂNCER (IBCC - \\ BRAZIL).
}

\footnotetext{
L. Leitão ${ }^{1}$, J. Sobrinho Campolina Martins ${ }^{1}$, T. Gomes de Almeida ${ }^{1}$, C. Baltazar de Sousa ${ }^{1}$, G. Lowndes de Souza Pinto ${ }^{1}$, A. Lopes de Farias e Silva ${ }^{1}$, F. Ricardo Gualda Coelho ${ }^{1}$, R. Lucio Rangel Costa ${ }^{1}$.

${ }^{1}$ Instituto Brasileiro de Controle do Câncer IBCC, Gynecologic Oncology, Sao Paulo, Brazil.
}

\section{OBJECTIVES:}

To trace a profile of patients with the diagnosis of uterine sarcomas, followed in the IBCC - Brazil, between the years of 2000 and 2017.

\section{METHODS:}

It was performed a retrospective analysis of the medical records and clinical charts of patients diagnosed with Uterine Sarcomas, which were treated in our institution between February 2000 and December 2017 to compare our results with the world literature.

\section{RESULTS:}

A total of 26 patients were included in the study. The definitive diagnosis (of uterine sarcomas) was made by anatomopathological examination associated with immunohistochemical analysis. The histological subtypes were allocated as: leiomyosarcomas $(53,84 \%)$, endometrial stromal sarcoma $(30,76 \%)$, adenosarcoma $(7,69 \%)$, fibromyosarcoma $(3,84 \%)$ and undifferentiated sarcoma $(3,84 \%)$.

The onset mean age found is 59,46 years (range: 30-91 years).
In many cases, the initial symptoms could be rather nonspecific, such as abnormal vaginal bleeding $(53,84 \%$, in which $64,28 \%$ presented postmenopausal bleeding) and abdominal or pelvic pain $(34,61 \%)$. In $11,53 \%$ of the cases, the onset symptoms were nonspecific. The totality (26 patients) of the patients were submitted to surgical treatment and $80,76 \%$ of them required adjuvant treatment. There was a global recurrence of $50 \%$ of the cases.

\section{CONCLUSIONS:}

Uterine sarcomas are rare tumors with poor prognosis with high risk of recurrence or metastases. The data collected in this review are consistent with what is shown in the world medical literature.

\section{REFERENCES}

Mbatani N, Olawaiye A, Prat J. Uterine sarcomas. Int J Gynecol Obstet. 2018; 143( Suppl.2): 51- 58.

Abeler VM, Royne O, Thoresen S, et al. Uterine sarcomas in Norway. A histopathological and prognostic survey of a total population from 1970 to 2000 including 419 patients. Histopathology. $2009 ; 54: 355 Y 364$.

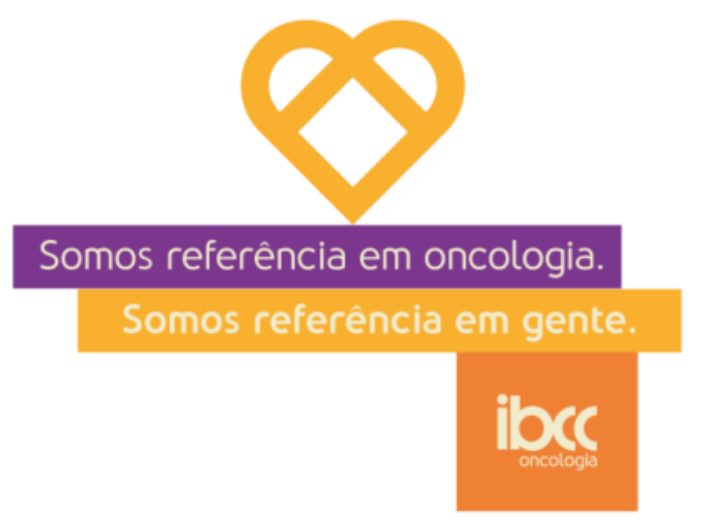

